\title{
An Overview of Some Vernacular Techniques in Iranian Sustainable Architecture in Reference to Cisterns and Ice Houses
}

\author{
Amir Ghayour Kazemi \& Amir Hossein Shirvani \\ Department of Architecture, Shahid Rajaee Teacher Training University, Tehran, Iran
}

\begin{abstract}
The great Iranian tradition is as yet little known in the West and there is much to be learnt both from it and the building techniques which are integral with it. Meanwhile, Not only is the Iranian vernacular building tradition itself still alive, but there is much to be gained from the knowledge of a highly developed technology which makes such ingenious use of natural resources without the consumption of additional power. This article is a study of the craftsmanship involved in the construction of the mud brick vernacular architecture of Iran, and the cultural aspects of a traditional architecture which incorporates an understanding of buildings which dates back centuries. Expanding the existing knowledge of these earthen heritage properties, examining their behaviour in the local climate and explaining their current condition in order to express the need for the preservation of traditional craftsmanship as part of a sustainable conservation future are the other prominent concerns of this work. Among different Iranian Vernacular constructions, Ice-houses and cisterns are the subject of the main body of this article.
\end{abstract}

Keywords: Vernacular techniques, Sustainable architecture, Iran, Ice-Houses, Cisterns

\section{Introduction}

Iranian vernacular architecture has developed over millennia in response to the Iranian plateau's arid climate, scarcity of acceptable building stone and wood, and extremes of temperature (Tavassoli, 2005). The ubiquitous building material is sun-dried brick and rammed earth. Building types include wind towers which exhaust warm air from buildings during the day; cisterns which are egg-shaped in section; ice houses with walls behind which water in shallow channels friezes at night; etc (Bourgeois \& Pelos, 1983). Some years ago, a huge legacy of fascinating and often beautiful vernacular buildings survived on the Iranian Plateau. Many occurred chiefly in the villages, but others had their grander counterparts in the towns. Some are either unique to Iran or may be prototypes of buildings elsewhere. Few Iranians or visitors have had time or inclination to look at such buildings, partly because the huge number which survived has tended to make them commonplace, but also because Iran has such a wealth of architectural and artistic treasure which has demanded prior attention. However, unless positive action is taken, most will have crumbled. Their rapid disappearance derives from a variety of good reasons. A redundant building, constructed of stone in a temperate climate, may survive many years as a ruin. (Kasmaie, 2006) But these Iranian buildings are chiefly built of unbaked mud-brick. Any mud-brick building quickly deteriorates without constant maintenance; this inevitably ceases once a building is no longer useful (Stronach, 1973). The fierce climate of the Plateau accelerates this process. Technological innovations of the first half of 20th century are the root cause of their redundancy. Modern refrigeration, new sources of power and the internal combustion engine have overtaken such buildings as ice-houses, mills and caravanserais. Landlord's houses and buildings such as hunting lodges have been neglected, both on account of absenteeism and also of land-reform (Hyde, 2000). Readers may notice that the literary sources noted in this article are confined in range. Few travellers, either today or in the past, have been sufficiently interested to record vernacular buildings. Those that have (notably John Fryer in the seventeenth century, C. J. Wills in the nineteenth and Hans E. Wulff in the twentieth) have shown a general interest in both Persian buildings and customs which is rare. The notes which follow are the result of researches from 2008 till 2010. During this time examples of the following types of buildings were noted, some briefly. They are listed here in the hope (justified by experience) that others, may have information to contribute (which would be much appreciated): ice-houses, cisterns, water mills, wind-catchers, windmills, animal mills, houses, hunting-lodges, agricultural buildings, pigeon towers and caravanserais. Ice-houses and cisterns are the subject of the main body of this article. Study of these buildings, motivates some instructive skills and cultural values in which the Iranians excel: 1) First, the design and execution of domes and vaults in mud-brick, which result in beautiful buildings, often constructed for mundane purposes. 2) Secondly, the Persian imagination and ingenuity, which is unrivalled in making the best use of water in a hostile desert environment. In this the Iranian contribution to the world's technology is probably unique. 3) Iranian traditional building techniques show an ingenious use of natural resources without the consumption of additional power. 4) Employing local materials in construction and repair work has many advantages as the original materials are close to the site. Meanwhile, these buildings contribute significantly to 
the economy by providing key attractions for tourism industry; and elimination of such traditional techniques equals the erosion of centuries of construction culture.

\section{Ice-Houses}

Ice houses were buildings used to store ice throughout the year, prior to the invention of the refrigerator. The most common designs involved underground chambers, usually man-made, which were built close to natural sources of winter ice such as freshwater lakes. During the winter, ice and snow would be taken into the ice house and packed with insulation, often straw or sawdust. It would remain frozen for many months, often until the following winter, and could be used as a source of ice during summer months. This could be used simply to cool drinks, or allow ice-cream and sorbet desserts to be prepared. The common use by the Persians of ice and snow for cooling drinks and food was reported by John Fryer in the late seventeenth century: They mightily covet cool things to the Palate. Wherefore they mix snow, or dissolve ice in their Water, Wine or Sherbets, (Aghdabiglo, 2001) he wrote (and of Isfahan) "... the Poor, have they but a Penny in the World, the one half will go for Bread, and dried Grapes, and the other for Snow and Tobacco ...". Outside Shiraz he saw that ice was stored in "Repositories" which he tantalizingly describes only as "fine buildings" but it seems likely that they were similar to the huge domed structures still to be seen in parts of Iran. Only a few survive, most as disintegrating ruins, although they were in common use only a few years ago. By Fryer's time the practice of storing ice was probably already long established, possibly having been introduced by the Mongols. (Ice-houses in China were known as early as the eighth century B.C.; they were probably small thatched buildings, like their successors there.)

In Britain, ice was not then considered to be a common necessity and was certainly not for the poor, but the ice-house was to become a feature of the great eighteenth-century estate, as it was in France. However, the English ice-house is as a bantam's egg to an eagle's when compared with those of the Iranian Plateau. There the great demand led to buildings of monumental scale and size. Fig.1 shows the Stour head ice-house, one of the larger English examples, drawn to the same scale as a typical Iranian ice-house at Yazd (Beazley, Jul 1963).However; the principles governing the design of each are the same: the ice has to be insulated and kept dry. The differing climates made insulation a far greater problem in Iran, and drainage of prime importance in damp, temperate Britain.

Obtaining the ice was another matter. Iran is not only largely desert, but fresh water is rare and even in winter, when the temperature falls to freezing at night, the mid-day sun is hot. Huge quantities of ice would be needed to fill these vast, domed wells. Some was brought as blocks of snow from the mountains, but the ingenious Persians, ever inventive in their masterly adaptation of desert conditions, had an imaginative and simple answer. Alongside each ice-house is a long shallow channel, about $100 \times 10 \mathrm{~m}$. and $40-50 \mathrm{~cm}$. deep, which is entirely shaded by a great wall, longer than the pool and as much as $12 \mathrm{~m}$. high; the wall is constructed of rammed earth and mud-bricks made from the earth which was excavated to form the channel. The channel is lined with tiles to make it watertight. C. J. Wills gives a clear description of ice-making in the latter part of the nineteenth century: The delicious AB-I-ROOKHI (stream of Rookhnabad) is diverted from its course on the first cold night. A few inches of still clear water is collected in the pond, by morning it is frozen, at night the water is collected in the pond, by morning it is frozen, at night the water is again admitted and another inch or two of ice is made. (Bourgeois, 1983).When three to six inches thick the ice is broken and collected for storage in a deep well on the spot; and so day by day the process goes on during the short winter, until the warehouses are full. Should the supplies from these be exhausted by a very large demand, ice, or rather blocks of snow, are brought from the mountains; but as these are some distance, and snow melts faster than ice, the weights being equal, the price rises (Dieulafoy, 1887). The ones who remember the work in icehouses say that on clear frosty nights water would be diverted from a stream to the ice pool. The ice formed was usually skimmed off in layers of about one inch. It was packed hard down, each layer insulated by straw (and presumably rammed as in Britain). Then the door was sealed and the ice kept until it was needed in summer. The man in charge of the ice-house would probably be responsible for the cistern in the village and might also look after the mosque. Villagers would be asked to contribute towards his wage and the repairs of the ice-house (Kasmaie, 2006).

The low cost of the ice and the way it was used was also explained by Wills. "The great thing in such a place is the cheapness of ice, for about $15 \mathrm{~s}$ in dear years and $5 \mathrm{~s}$. in cheap ones, ice can be obtained all through the warm weather, and in fact is used from May to October, as no one would think of drinking anything uncooled. A huge block is thrown down each morning by the ice seller-it is supposed to weigh $14 \mathrm{lbs}$." The ice-house is best understood from the illustrations. Barely half-a-dozen have been seen, although hundreds must have been in use even sixty years ago, particularly in the vicinity of rich cities on the edge of the desert, like Yazd, and on caravan routes. Those measured ranged from 9 to $14 \mathrm{~m}$. in internal diameter. The overall internal height of that at Yazd is c. $19 \mathrm{~m}$. The disused ice-houses had often been used as rubbish dumps so it was not possible to investigate the 
method of drainage (if any). One or two had boldly decorated walls, the bricks near the top being laid in open checkered patterns and the tops crenellated. Most spectacular perhaps was the pair of ice-houses found on the outskirts of Sirjan; the ice-walls which linked them curved to give extra shade, giving a plan form like some huge winged creature.

Although a mass of nineteenth century literature is available on English ice-house construction, notably in garden encyclopedias such as Loudon's, or in books like Pap worth's Rural Residences, almost nothing seems to have been written on examples outside Europe. The notable exception is the redoubtable Mrs. Fanny Parkes, whose Wanderings of a Pilgrim in Search of the Picturesque gives a vivid account of life in India in the second quarter of the nineteenth century. She describes the ice-pits of Allahabad: "My husband has the management of the ice concern this year. It is now in full work, the weather bitterly cold, and we are making ice by evaporation every night." At first glance, the principle might be thought to be similar to the Iranian method, the word "evaporation" perhaps having crept in unnecessarily. But such assumptions are shown to be wide of the mark by the unexpected statement of this careful author: "The highest temperature at which ice was made in 1846 at Cawnpore was $43^{\circ}$ of Fahrenheit or $11^{0}$ above freezing point (Locke, 1975). Her drawing shows that the ice was not made in the channel as in Iran. Instead, the channel or pit, which was a cubit deep, was filled with dry straw; on it were placed small bowls which were filled from pitchers and the ice was made in these. (Cultural research association, 2007) Presumably the bowls were porous; evaporation would lower the temperature of the water and the dry straw would insulate the bowls from the heat radiated from the ground-on a still clear night the temperature of the water could be several degrees lower than that of the air immediately above the surrounding ground. Even so, this explains nothing fully, and it would be interesting if any reader could provide a complete answer. Mrs. Parkes reported that her husband's work went on until February 19th, by which time over 107 tons of ice had been made. It was stored in small thatched buildings similar to those used in China. This single Indian example makes one wonder whether there is not more to be learnt about Persian techniques than might at first be imagined. Although modern methods of refrigeration have made the ice-house obsolete in Persia, there are still people who can remember its use. (Fig.2)

\section{How the building works}

The long shallow channel to the north of the shade walls is poured with water during the winter nights, when the weather is so cold in Iranian desert. As the temperature of the earth and the water is higher than the sky during the night hours, the water will loose its heat and can easily freeze till next morning. The amount of water in the shallow channel depends mostly on the clouds. If the weather is so cloudy, the depth of the water in channel would be less so that it can freeze easier. (Clouds act as an isolation layer for the exchange of cold and heat) Before the sun rises, the ice made in channels are crashed into pieces as the smaller pieces loose heat better than the bigger ones. They are moved to the vast domed wells afterwards. The depth of the wells stabilizes the temperature. So during the day, the changes of temperature would not affect the ice pieces. On the other hand, the height of the dome above the well lets the inner hot air stay at higher levels during the day while the lower parts are still cold. The material used to construct the building is from rammed earth with mud bricks which avoids the heat passes through the ice house easily during the day. Meanwhile it's made from the earth which was excavated to form the channel. So it's beneficial too. High mud brick walls to the north of the domes are used to spread a vast shaded area on the channel during the day. So it avoids the earth on the channel area to absorb the heat as much as the other parts. Therefore, the water could freeze sooner during the night. Here are diagrams analyzing the flow of hot and cold air in the building. (Fig.3)

\section{Cistern / Water Storage:}

Water storage is a traditional reservoir of drinking water in Persian antiquity. The Persian phrase literally translated as "water reserve". Persian prowess in the skill of water collection and storage is based on long experience. Indeed, the qanat system was recorded during the reign of Darius I, and qanats now in use in the south of the Sahara are known as "Persian work". The qanat, or underground water channel, through which water is carried by gravity from a water-bearing stratum at a higher level (usually near the base of mountains) to a village or oasis on the Plateau, has been recorded by many travellers, so will only be mentioned briefly here. A qanat is beautifully simple in its basic conception, but the skill of those who plan and construct these ingenious tunnels is hard to exaggerate (Fryer, 1963). Certainly an understanding of the system, both its potential and its limitations, is essential to the appreciation of settlement on the Plateau. It accounts for flourishing settlements many miles from any source of water, and for the collapse of the same towns and villages if the life-giving qanat has been cut either by a natural disaster or the hostility of an enemy (Herbert, 1928). The fascination of the qanat has led more recent travellers to ignore other less spectacular systems of water collection, such as that of the conservation of sheet wash in the desert: the trapping of the flood water following the rare but heavy rainstorms 
which occasionally occur in areas of otherwise arid plateau. Indeed, no traveller would choose to be on the road following such weather, so it is hardly surprising that only one reference has been found. This again comes from that indomitable seventeenth century recorder John Fryer: "... the other [method of obtaining water] is immediately from the Heavens, reserved in cisterns built by the charity of well-disposed persons; out of which the Poor, the Covetous, and Slaves, Flocks and Herds too, are often supplied, when a plentiful Rain has made them overflow..." (Ibid, 2003). It was only after careful examination of the ground that isolated structures (Figs.4a-c) which we thought to be desert shelters were recognized to be cisterns-this function having first been dismissed since there seemed to be no source of water supply. Low banks of earth and stone (often less than a meter high) contain the water, which is guided by an almost imperceptible fall in the ground towards the cistern. The water flows in through a hole at ground level and is taken out as needed by a bucket through a small door. The cistern is protected from the sun by a dome or vault depending on its shape. Before the internal combustion engine put the caravan and mule out of business, such cisterns seem to have been common along some of the caravan routes. Now they are increasingly rare. But a few villages and small towns may still rely partially on this system. For instance, there are six large cisterns, two of which seem to be new, outside the desert town of Khor; it seems that these were constructed to collect sheet wash. Numerous smaller ones, mostly derelict, were seen along the road Nain-Chupanar-Khor. The occurrence of numerous cisterns in varying states of repair also mystified Fryer "... These Cisterns or Storehouses for Rain are digged out of the Ground deep into the Earth ... which being once finished, like their caravan seraws have no Endowment to maintain them, either to keep them clean, or from falling to Decay: ... on which account it is, that about their great Cities so many of all sorts are found, newly built, superannuated, defiled (which they esteem so, if either Man or Beast have dropped in and been drowned), unfrequented, and full of Nastiness; so pervicaciously Vainglorious, that they will have the Repute of an entire Founder, or none." Clearly, the problems of endowment and maintenance are neither new nor local, but the capital cost of building by traditional methods is comparatively economic in Iran. However, any qanat system is clearly preferable to such a haphazard means of water collection as that from sheet-wash so it is hardly surprising that those cisterns fed by qanats are usually bigger and better constructed (Ghobadian, 2001). One excellent example seen in 1981 had only recently been built. Like others in the province of Yazd it is cooled by three wind-catchers or wind-towers, and this functional architectural composition is unexpectedly satisfactory. The design seems typical of a fairly wide area: a deep, circular well, about five meters in diameter, is protected from evaporation and dust by a dome. The simple form of the egg-shaped dome contrasts nicely with the vertical towers which rise above the crown of the dome in order to catch the wind. A vaulted porch is often constructed to shade the upper part of the underground flight of steps which leads down to the well. The covering of the surface of the cistern is the most difficult part of the construction because to cover openings of 15 to $16 \mathrm{~m}$ width needs a lot of experience, but this is done by resorting to bends and the elliptical arches which prevent the expelling force (Hyde, 2000). (Figs.5-6)

\section{Conclusion}

Iran's traditional architecture is designed in proportion to its climatic conditions, and more than often, the unique fabled artistic background of Persia makes up for the seemingly lack of natural resources and beauty (Kasmaie, 2006). Traditional building techniques are particularly important because they are the result of centuries of development and practice. The recording of craftsmanship is extremely vital, not only because it provides empirical evidence of original practice, but also because it can be directly applied to practical conservation. Employing local materials in construction and repair work has many advantages, not least of which is the fact that the sources for the original materials are close to the site. Furthermore, it is explained that the workmanship necessary for using traditional materials such as mud requires more skill, sensitivity and grounding in traditional culture than what is required for modern materials. The intermediate technology is now seen by many to be an essential ingredient of progress in the 21 st century. This great Iranian tradition is as yet little known in the West and there is much to be learnt both from it and the building techniques which are integral with it. It is the fate of vernacular buildings throughout the world to be neglected until they are nearly extinct. The Folk Museum and the Museum of Buildings are relatively new ideas in Europe, where they are thought of primarily in terms of conservation and education in history and the arts. In Iran their value could be even greater since these functions could be combined with those of an institute of intermediate technology. Not only is the building tradition itself still alive, but there is much to be gained from a knowledge of a highly developed technology which makes such ingenious use of natural resources without the consumption of additional power. The Persian ice-house with its great shade wall could hardly be described as small, but the technology it represents is certainly beautiful in its simplicity. Water collection and its storage in desert conditions and air-conditioning by means of wind-catchers are living skills which the Iranians might pass on to others. However, unless positive action is taken, most 
Iranian Vernacular buildings will have crumbled. Thus, In the name of Iranian architectural heritage, it is hoped that any further decay of such historical constructions can be prevented by funding.

\section{References}

Aghdabiglo, Z. (2001). Passive cooling system, PhD thesis, Sydney University, pp. 76-9.

Beazley, E. (Jul 1963). Greek mills in Shetland, The architectural review, CXXXIV, pp.62-4.

Bourgeois J, Pelos C. (1983). Spectacular Vernacular: A New Appreciation of Traditional Desert Architecture, New York, published by Peregrino Smith Books, pp. 67-71.

Cultural research association. (2007). The Iranian Atlas of Vernacular Architecture, published by Cultural research association, pp.71, 93 and 114 .

Dieulafoy, J. (1887). la perse, la chaldee et la susiane, Paris, P.680.

Fryer, J. (1963). A new account of the east Indies and Persia being nine years travels 1672-81, Vol.3, Tehran, published by Cultural research association, p.149.

Ghobadian, V. (2001). Climatic Analysis of the Iranian Traditional Buildings, Tehran, Tehran University Publications, pp. 308-37.

Herbert T. (1928). travels in Persia, 1627-29, London, published by Broadway travelers' edition, p.143.

Hyde, R. (2000). Climatic Responsive Design, New York, E \& FN SPON publications, pp.97-112.

Ibid. (2003). Vol.2, pp.218-48,168.

Kasmaie M. (2006). Climate and Architecture, Tehran, published by the Iranian Construction-Co, pp.54-8.

Lambton, A. (1953). Landlord and Peasant in Persia, London, published by Broadway travelers' edition, p.143.

Locke, G. (Autumn. 1975). "Icehouse", National trust newsletter, No.24, p.20.
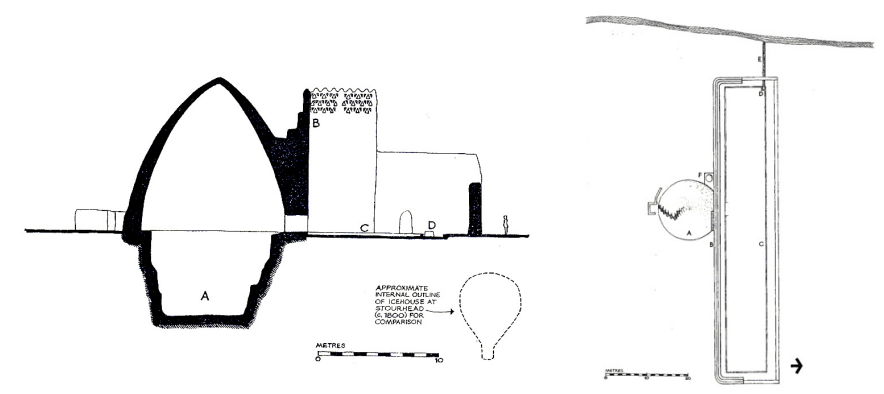

Figure 1. Icehouse at Yazd: Plan and section [Authors]

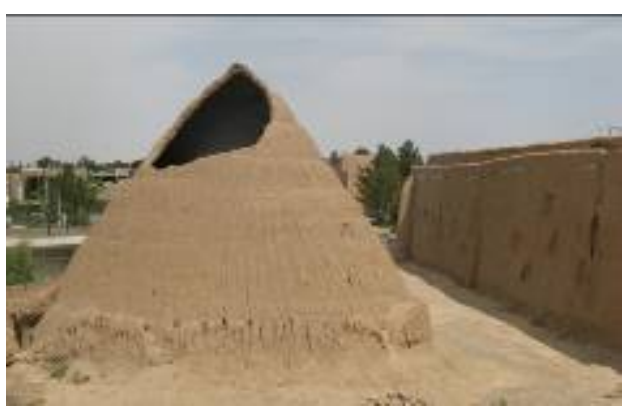

Figure 2. Remains of an Icehouse near Kashan [Authors] 

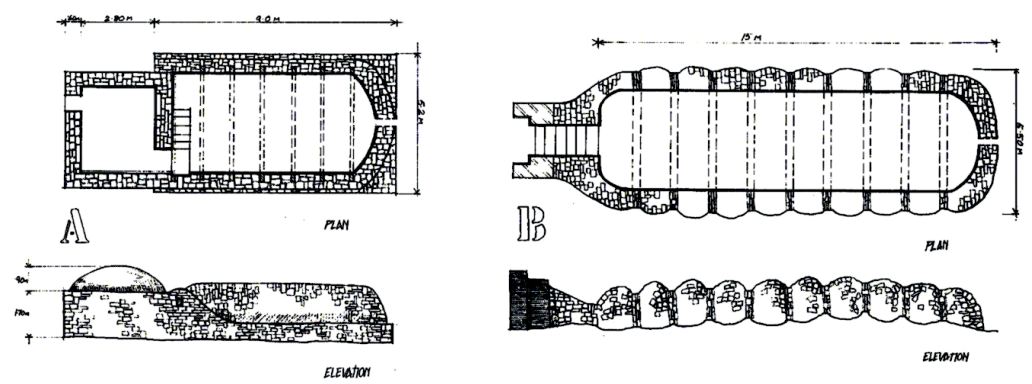

Figure 3. Climatic analyses of the Ice house [Authors]
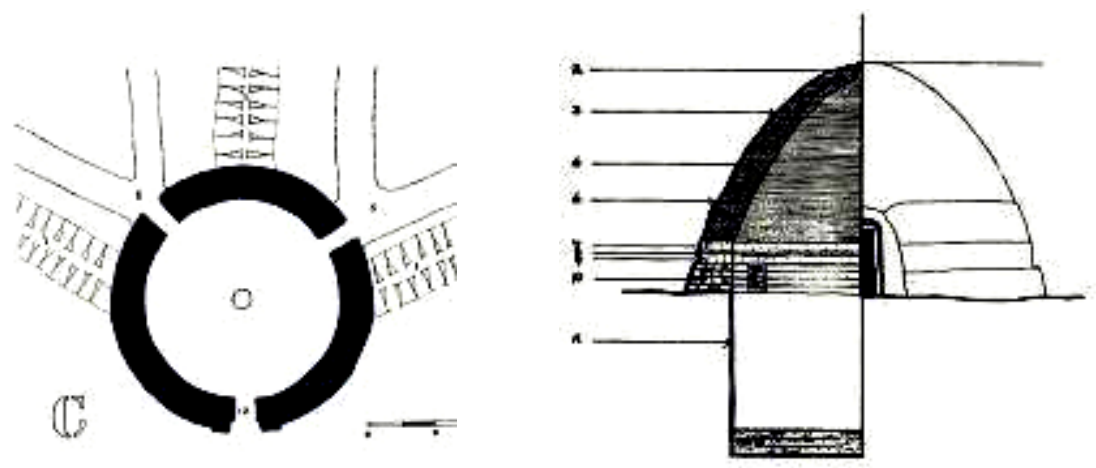

Figure 4. A and B. Desert cisterns fed by sheet wash [Authors]

Note: A and B near Muhammadiyyeh.

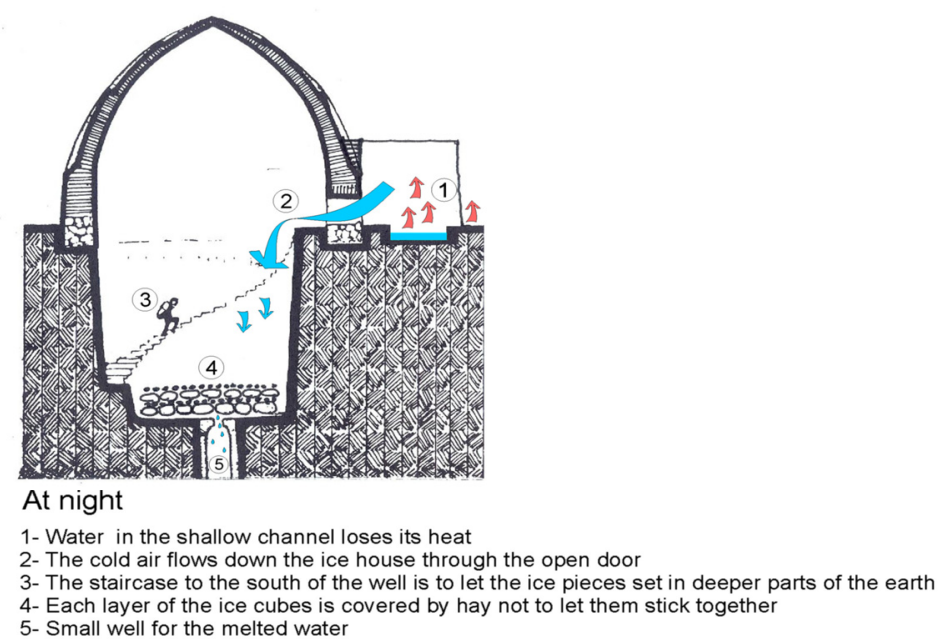

Figure 4 C. Desert cistern near Chamale: [Authors]
1. Earth banks, c. $1 \mathrm{~m}$. high.
6. Maintenance step
2. Central hole, $30 \mathrm{~cm}$. dia.
7. pise.
3. External mud plaster finish.
8. Mud brick course
4. Mud brick dome
9. Stone base
5. Intel channel
10. Waterproof plaster lining 


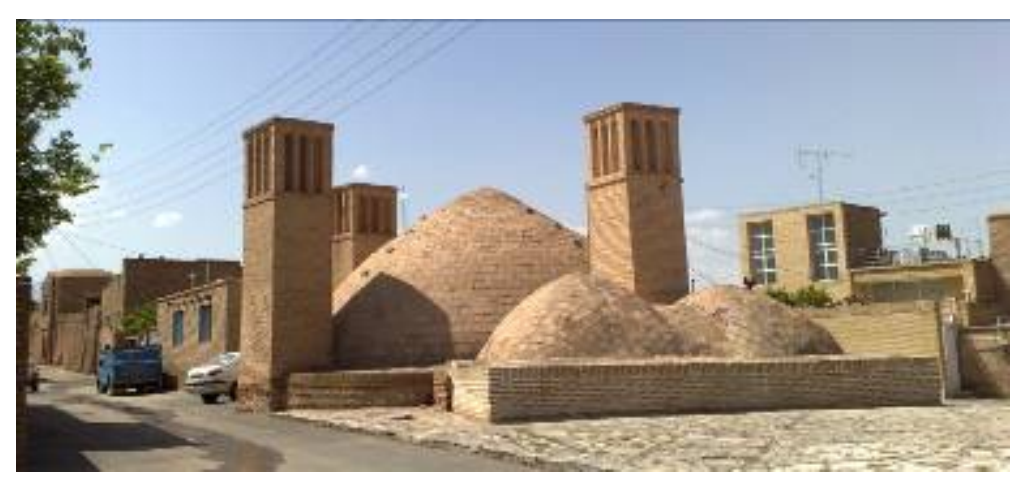

Figure 5. A new cistern with three wind-catchers, near Yazd [Authors]
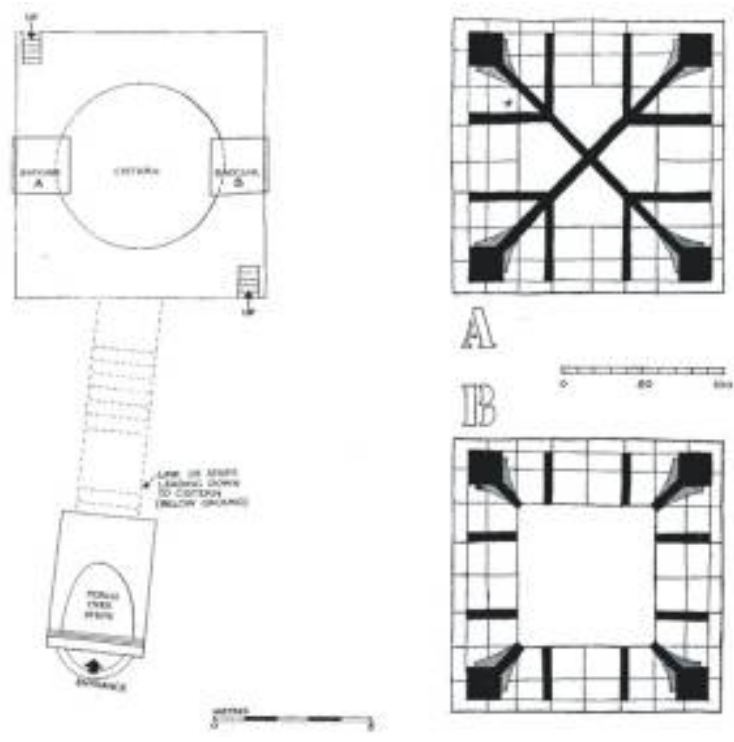

A

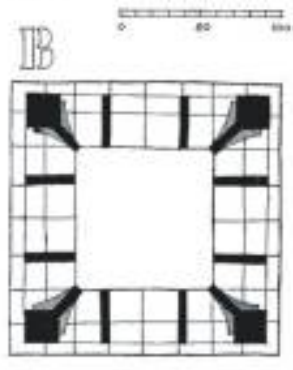

Figure 6. A cistern cooled by wind-catchers, Muhammadiyyeh;

Roof plan and detailed plans of wind-catchers at ventilator level. [Authors] 